\title{
THERMAL FATIGUE AND FAILURE OF ELECTRONIC POWER DEVICE SUBSTRATES.
}

\author{
S. Pietranico ${ }^{1 \& 2}$, S. Pommier ${ }^{1}$, S. Lefebvre ${ }^{2}$, S. Pattofatto ${ }^{1}$ \\ ${ }^{1}$ LMT-Cachan, ${ }^{2}$ SATIE, (ENS Cachan/CNRS/UPMC/UniverSud Paris), 61, avenue du \\ Président Wilson, 94235 Cachan, France
}

\begin{abstract}
Electronic power devices used for transportation applications (automotive and avionics) experience severe temperature variations, which promote their thermal fatigue and failure. For example, for power modules mounted on the engine of an aircraft, temperature variations range from $-55^{\circ} \mathrm{C}$ (in the worst case of storage before takeoff) to $+200^{\circ} \mathrm{C}$ (flight). Direct bonded copper (DBC) substrates are used to isolate chips (silicon dies) from their base plates. For large thermal amplitudes, the failure occurs in DBC substrates, which are copper/ceramic/copper sandwiches. The Weibull approach was used to model the brittle fracture of the ceramic layer from a natural defect. Furthermore, geometric singularities in the upper ceramic/copper interface are at the origin of cracks that grow by fatigue along the interface and finally bifurcate and break the ceramic layer. It is discussed how the framework of linear elastic fracture mechanics (LEFM) can be used to characterize the stress field around singularities and the associated risk of failure. These two criteria and the finite element method, allow analysing how a thermal loading history may modify the risk of failure of DBC substrates. It was shown, in particular, that three overcooling cycles should produce an "overload retardation effect". Experimentally, applying 3 "overload cycles" ($\left.70^{\circ} \mathrm{C},+180^{\circ} \mathrm{C}\right)$, prior to thermal fatigue cycles $\left(-30^{\circ} \mathrm{C},+180^{\circ} \mathrm{C}\right)$, increased very significantly the fatigue life of DBC substrates. This result shows that the fatigue life and the reliability of power electronic devices could be optimized using a thermo-mechanical approach of the problem and suitable failure criteria.
\end{abstract}

Keywords: Variable amplitude fatigue, overloads, Weibull, LEFM, aluminium nitride, copper.

\section{Introduction}

Power semiconductor modules are mainly used for controlling electric motors, especially in transportation applications (automotive and avionics). Improving the reliability and the fatigue life of high power electronic devices is a real challenge for these applications in which power modules are increasingly used, in particular for purposes of reducing the fuel consumption of engines. In many of these applications, power modules experience cyclic temperature variations. Two types of 
thermal cycles are superimposed, power cycles coming from the application of electric current in the active parts of the modules during the phases of operation (Joule effect) and passive cycles stemming from ambient temperature variations. In the environment of an aircraft engine, these variations are typically between $-30^{\circ} \mathrm{C}$ and $+180^{\circ} \mathrm{C}$ and in the worst cases between $-55^{\circ} \mathrm{C}$ to $200^{\circ} \mathrm{C}$. Therefore, power electronic devices are highly vulnerable to variable amplitude thermal fatigue. The aim of this research is to understand the mechanisms at the origin of failure and to model them so as to optimize either the geometry or the manufacturing process of power modules in order to improve their fatigue life and their reliability

The studied modules are composed of chips, ceramic substrates and base plate [1]. Chips are soldered on ceramic substrates which are themselves soldered on base plates. Ceramic substrate ensures the electrical insulation of the chips from the base plate. The substrate must also allow the evacuation of the heat resulting from power dissipation, from chips to the base plate. For this purpose, aluminium nitride Direct Bonded Copper (DBC) substrates are commonly used in power modules, because of their good thermal conductivity. They are composed (Fig. 1) of a ceramic layer (aluminium nitride) with a thin sheet of copper bonded to both sides by a high-temperature oxidation process. The upper copper layer (thickness $t_{\mathrm{Cu} 1}=127 \mu \mathrm{m}$ to $300 \mu \mathrm{m}$ ) is then chemically etched so as to form an electrical circuit. The ceramic tile (thickness $t_{\text {AlN }}=635 \mu \mathrm{m}$ ) ensures the electrical insulation and the lower copper layer is kept plain and soldered onto the base plate (copper or AlSiC) mounted on a heat spreader. The global thermal expansion coefficient of a DBC substrate is close to that of a silicon chip which reduces the effect of thermal cycling at the interface between the chip and the substrate. Conversely, and especially for the highest temperature variations, thermal fatigue failures appear inside the DBC substrate and limit the fatigue life of the module [1].

Therefore, the thermal fatigue of the DBC substrate was analysed. The difference between the thermal expansion coefficients of copper and aluminium nitride is at the origin of thermal fatigue. It was observed that cracks are either initiated directly from the layer of ceramics or from geometric singularities in the DBC substrate [1,10]. In the latter case, the failure of the ceramic layer occurs after several cycles, according to the temperature range (Fig. 1 b, Fig. 2). In the first case, if the temperature variation is large enough, a through thickness crack appears in the ceramic layer (Fig. 1 a). The two mechanisms compete to break the DBC substrate and are examined independently. 


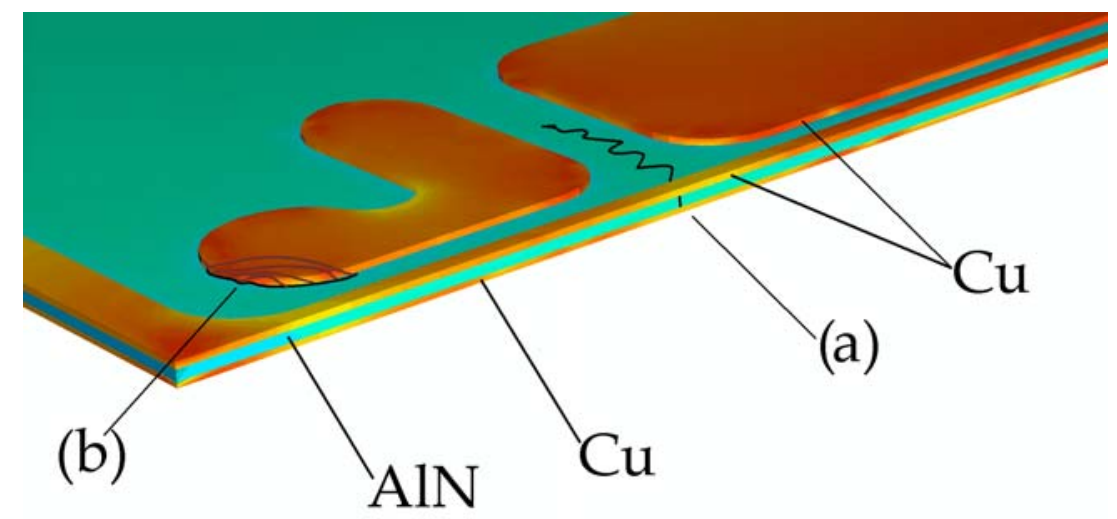

Fig. 1: Schematic of a DBC substrate and of its failure modes. The upper and lower layers are made of copper, and isolated by a layer of ceramic (AIN). The upper copper layer is chemically etched so as to print a circuit. (a) through thickness fracture of the ceramic layer. (b) interfacial crack growth at the upper copper/ceramic interface, followed by the fracture of the ceramic layer.

In this paper, the two failure mechanisms are characterized and modelled independently and finally, a finite element model of the DBC substrate is set up and used to propose a method to improve the fatigue life of the modules. This solution was also tested experimentally.

\section{Failure mechanisms.}

In the manufacture of power modules, the DBC substrates are first soldered to the base plate. During the soldering operation, the temperature in the $\mathrm{DBC}$ reaches a temperature around $250^{\circ} \mathrm{C}$ for high temperature applications (avionics, for instance). Then the modules are cooled down to ambient temperature and, according to the profiles of mission, the temperature of the substrate varies typically between a minimum bound of $-55^{\circ} \mathrm{C}$ and a maximum bound of $+200^{\circ} \mathrm{C}$. In this study, the thermal cycles used to test DBC substrates are rather severe, since they have been chosen close to the most severe constraints, with a minimum temperature of $-30^{\circ} \mathrm{C}$, a maximum temperature of $180^{\circ} \mathrm{C}$, a rate of $\pm 10^{\circ} \mathrm{C} / \mathrm{min}$ and a 15 minutes dwell time. The capacitance between upper and lower elements of the DBC is used as an ageing indicator. Periodically, the capacitance is measured (Fig.2 a). In a previous study, using the same substrates and the same experimental conditions, L. Dupont [1] showed that the capacitance remains nearly constant during 20 cycles. Then the capacitance drops down and the failure occurs at the $40^{\text {th }}$ cycle (Fig. 2 b). 


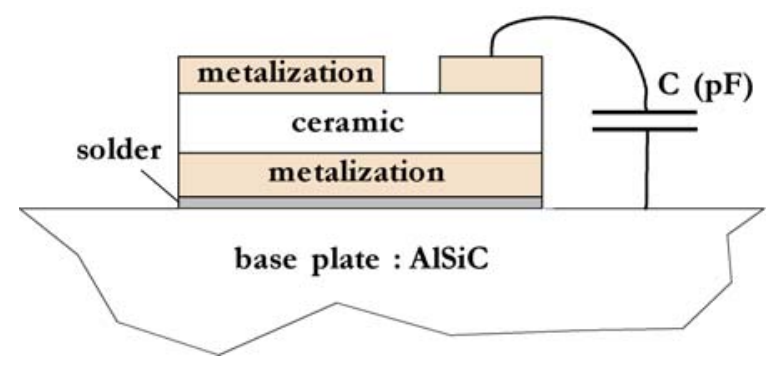

(a)

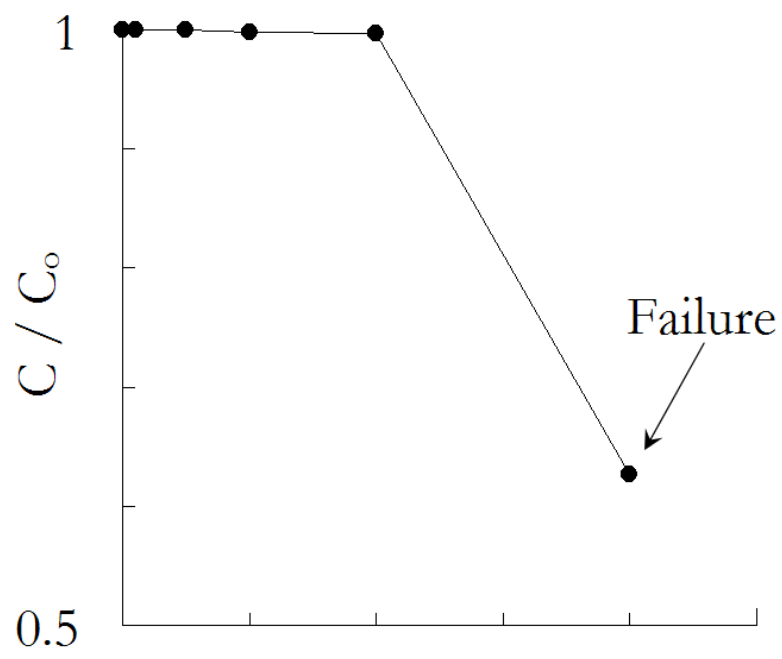

0
$\mathrm{N}$

(b)

Figure 2: (a) Measurement of the capacitance $C(p F)$ of the substrate. (b) Results [1], Capacitance $C$, non-dimensioned by the initial capacitance $C_{o}$ versus the number of thermal cycles $\left(T_{\min }=-30^{\circ} \mathrm{C}\right.$ and $\left.T_{\max }=180^{\circ} \mathrm{C}\right)[1]$.

Broken substrates were observed in a low vacuum scanning electron microscope in order to identify the mechanisms that lead to failure. Cracks initiate from geometric singularities created by the chemical etching of the upper copper layer (Fig. 3 a). This technique is used to print the electrical circuit in the upper copper layer. In Fig 3 a, the local angle at the sharp corner is around $120^{\circ}$, but it varies along the etching front. A very large number of tiny cracks were found all along the etching front, with a typical depth of 50 to $80 \mu \mathrm{m}$ (Fig. 3b). These cracks lie within the copper layer, near the interface.

On the fracture surface, fatigue striations are clearly visible and can be counted. The number of visible striations is close to the total fatigue life (40 cycles) of the substrate, which implies that the life of the modules is controlled by fatigue crack growth in copper near the copper/ceramic upper interface. The initiation phase can be neglected in this case. Then the crack bifurcates and a brittle fracture of the ceramic layer is observed (Fig.3 d).

The main conclusion of these observations is that the thermal fatigue life of the DBC substrate is controlled by the growth of a fatigue crack in copper from a geometric singularity and near the copper/ceramic upper interface. Finally, when critical conditions are reached the crack bifurcates and breaks the ceramic layer. 


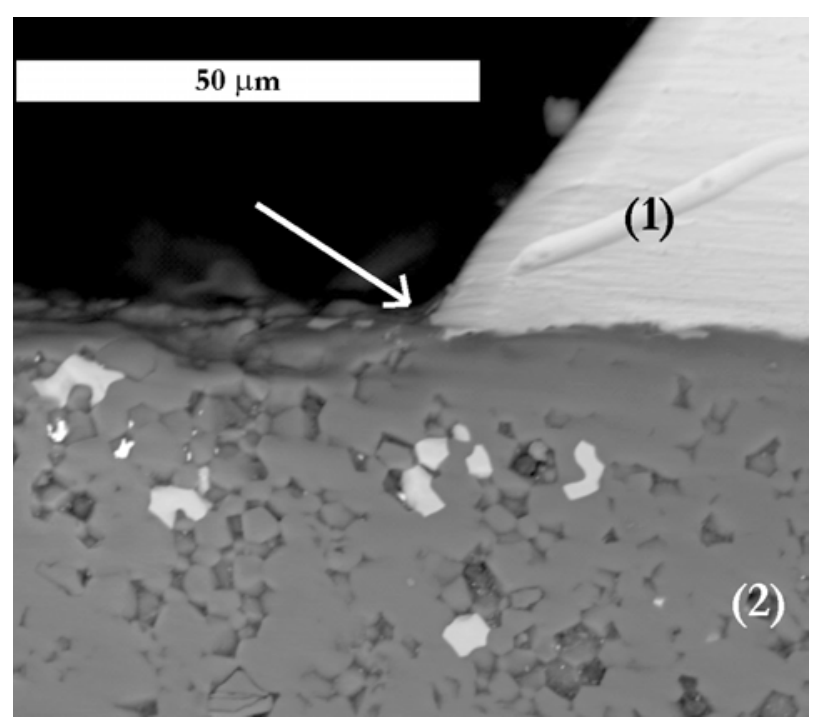

(a)

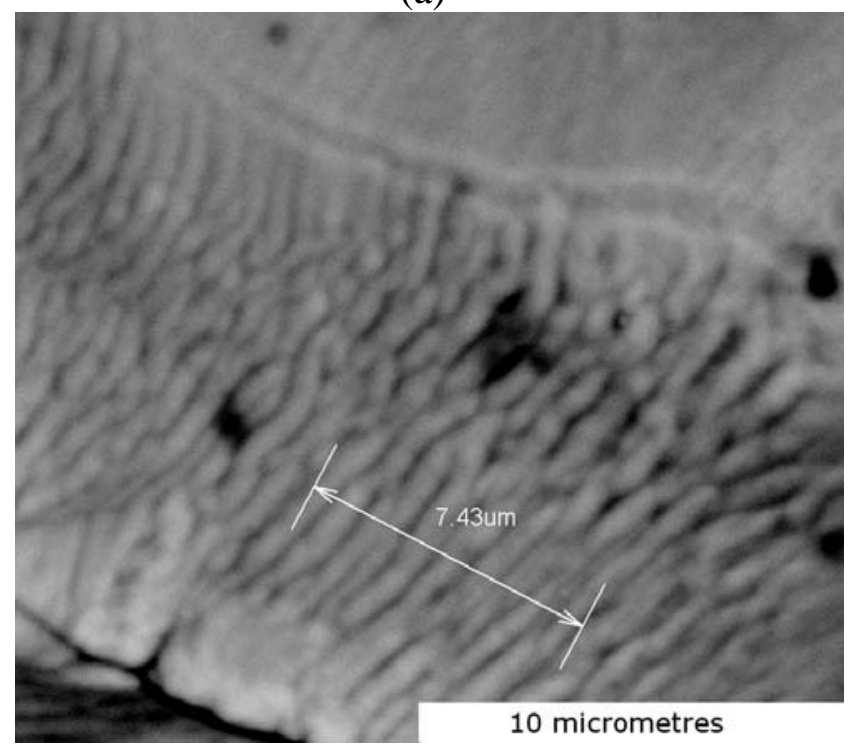

(c)

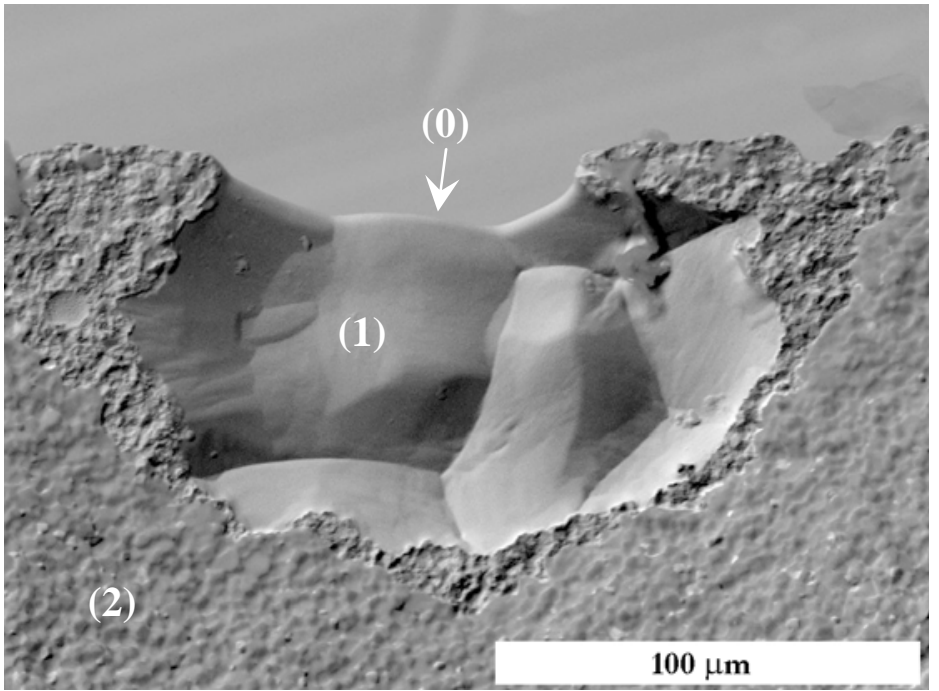

(b)

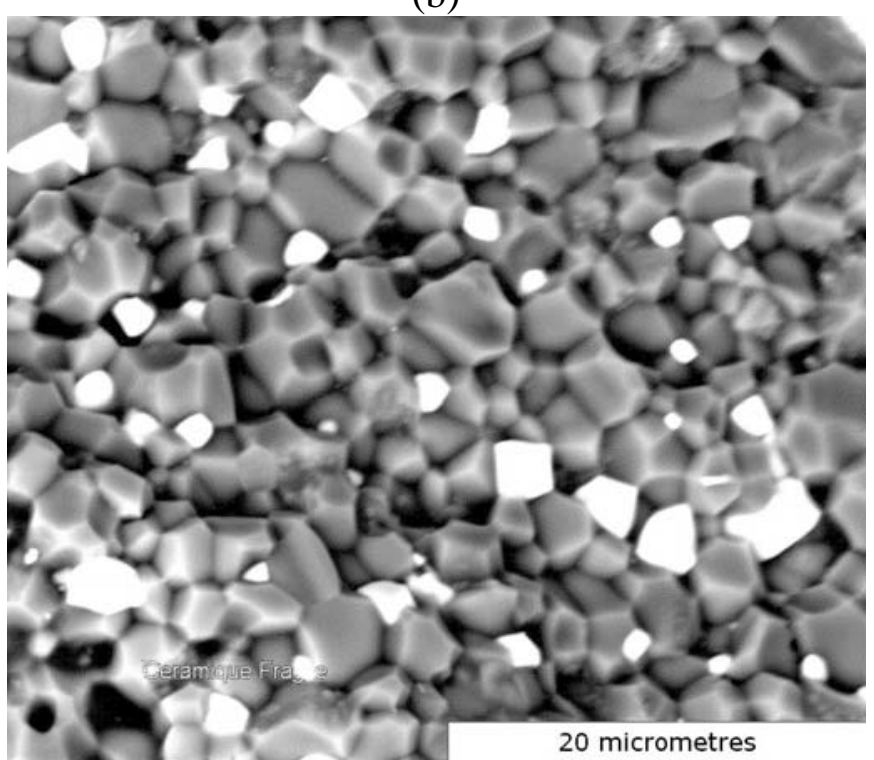

(d)

Figure 3: SEM images. (a ) detail of a transverse section of the DBC substrate at the copper/ceramic upper interface, near a geometric singularity created by chemical etching. (b,c,d) Fracture surfaces. (b) a small fatigue crack in copper : initiation (0), fatigue crack growth in copper (1), brittle fracture of the

ceramic layer (2). (c) detail of zone (1), fatigue striations are visible. (d) detail of zone (2), brittle fracture of the ceramic layer in the ceramic layer (BSE).

The second possible failure mechanism is a brittle failure of the ceramic layer from a natural defect of the ceramic. In such a case, the crack is orthogonal to the maximum principal stress direction, i.e. to the interface plane (Fig. 1 a).

So as to optimize the geometry of the DBC or its manufacturing process, these two failure mechanisms are characterized and modelled independently by two failure criteria. Then the two failure criteria can be used to determine how a change in the geometry or in the thermal history may modify the risk of failure and the fatigue life of the DBC substrate. 


\section{Brittle fracture of the ceramic layer.}

First, the failure criterion of the aluminium nitride ceramic layer is determined, because the fracture of the ceramics layer ends the life of the electronic device. Two criteria are used according to the nature of the initiation site.

The brittle fracture can be initiated from a geometric defect. This is the case for instance in Fig. 3b, where the initiation site for the brittle fracture of the ceramic is a tiny crack, which was created in copper by thermal fatigue cycling. In such a case, provided that the LEFM framework can be used, the final failure occurs when the maximum value of $K_{I}$ reaches the fracture toughness of the ceramic $\left(K_{I C} \approx 4 M P a \sqrt{m}\right)[2]$.

In addition, the brittle fracture of the ceramic layer can also occur from a material defect of the ceramic itself such as a grain boundary, a micro-crack or a pore. These defects being statistically distributed in the ceramic layer, the fracture strength is also statistically distributed. A probabilistic approach is therefore employed as a fracture criterion from natural defects in the ceramic layer.

\subsection{Weibull law}

To represent the random nature of the tensile strength of the material, the Weibull law and the weakest link theory are employed:

$$
P_{F}=1-P_{S}=1-\exp \left(-\frac{d V}{V_{o}}\left(\frac{\sigma}{\sigma_{0}}\right)^{m}\right)
$$

The probability of failure $P_{F}$ is function of the value of the maximum positive principal stress $\sigma$ component in a given volume of material $d V \cdot V_{o}$ is used to non-dimension the volume of tested material $d V$ and is fixed arbitrarily at $V_{o}=1 \mathrm{~mm}^{3}$.

For a given stress $\sigma$, if the volume of tested material increases, the probability of failure increases also, which is consistent with the fact that the probability of finding a critical defect for that stress level increases when the volume material increases. In addition, for a given volume of material $d V$, the probability of failure increases when the stress increases. The two parameters $\sigma_{o}$ and $m$ control the statistic distribution of tensile strengths. 
Experiments were performed in order to identify $\sigma_{o}$ and $m$ for the AlN ceramic used in the power modules.

\subsection{Experiments}

Samples of ceramic of different geometries have been characterized. Three points bending tests were used for this purpose (Fig. 4). The distance $L$ is equal to $19 \mathrm{~mm}$ in all cases. The thickness $t$ of the samples is either equal to $0.5 \mathrm{~mm}$ or $1 \mathrm{~mm}$. Their width $w$ is either $2.5 \mathrm{~mm}$ or $10 \mathrm{~mm}$. In a three point bend test, the stress is calculated as follows as a function of the maximum stress $\sigma_{\max }$ :

$$
\sigma(x, y)=\left(1-\frac{2|x|}{L}\right) \frac{2 y}{t} \sigma_{\max } \quad \text { where } \quad \sigma_{\max }=\sigma\left(0, \frac{t}{2}\right)
$$

The maximum value of the stress gradient $(d \ln \sigma / d y)$ in the sample is equal to $(2 / t)$.

According to the weakest link theory, the survival probability of the sample is the product of the survival probability of each sub-volume inside the sample. Thus, taking into account the Weibull law (Eq. 1) the failure probability is as follows:

$$
P_{F}(V)=1-P_{S}(V)=1-\exp \int_{V}-\frac{d V}{V_{o}}\left(\frac{\sigma(x, y)}{\sigma_{0}}\right)^{m}=1-\exp \left(-\left(\frac{\sigma_{W}}{\sigma_{0}}\right)^{m}\right)
$$

Where:

$$
\sigma_{W}=\sigma_{\max }\left(\frac{V_{e f f}}{V_{o}}\right)^{1 / m} \quad \text { and } \quad V_{e f f}=\int_{V}\left(\frac{\sigma(x, y)}{\sigma_{\max }}\right)^{m} d V=\left(\frac{V}{2}\right) \frac{1}{(1+m)^{2}}
$$

It is useful to use samples with different geometries in order to determine precisely the effect of a volume change on the fracture strength. More than one hundred specimens were broken to characterize the Weibull law. The broken samples are classed by increasing values of $\sigma_{\mathrm{W}}$, so as to determine their failure probability. Since $\sigma_{\mathrm{W}}$ is function of $m, m$ was optimized step by step so as to get finally all the results lying on the same curve.

Finally, a very good agreement is found between the set of experimental results and a Weibull law with $\mathrm{m}=10.3$ and $\sigma_{0}=368 \mathrm{MPa}$ (Fig. 4 c). With these parameters, if an AlN sample is subjected to a uniform stress, a probability of failure of 0.63 corresponds to a tensile stress of $368 \mathrm{MPa}$ if $\mathrm{V}=1 \mathrm{~mm}^{3}, 450 \mathrm{MPa}$ if $\mathrm{V}=0.1 \mathrm{~mm}^{3}$ and $300 \mathrm{MPa}$ if $\mathrm{V}=10 \mathrm{~mm}^{3}$. 
It is important to note that the smallest effective volume $V_{e f f}$ used in these experiments is equal to $0.07 \mathrm{~mm}^{3}$. It is therefore possible to use this model to predict the failure probability of AlN for any volume of material larger than $0.07 \mathrm{~mm}^{3}$, but it is not safe to extrapolate this model to smaller volumes. Similarly, the maximum value of the stress gradient $(d \ln \sigma / d y)$ in the experiments is equal to $4 \mathrm{~mm}^{-1}$. When the model is used, the domains where the stress gradient exceeds this value should be excluded of the analysis.

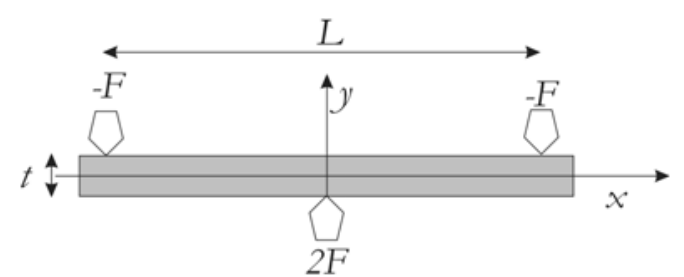

(a)

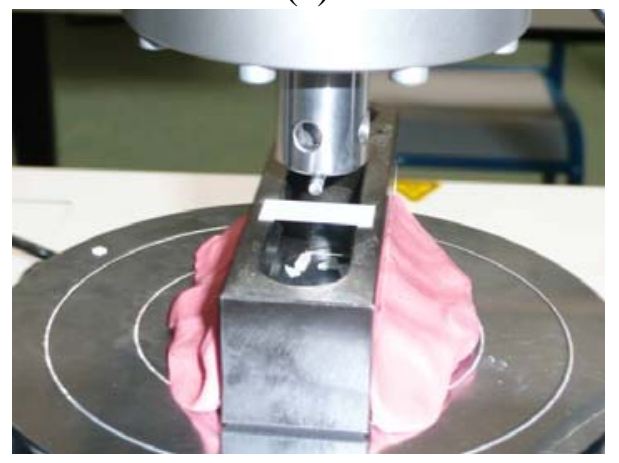

(b)

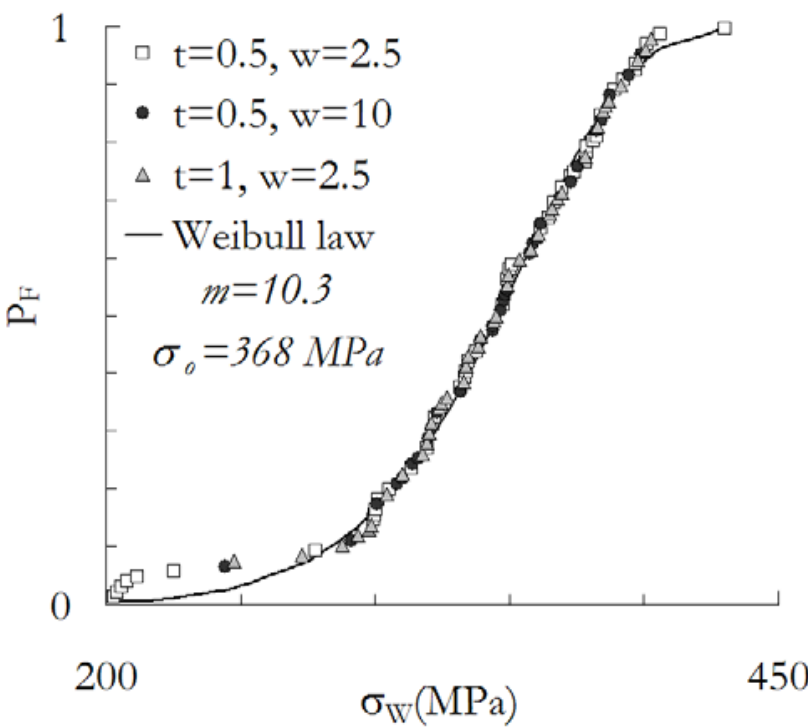

(c)

Figure 4: Three points bending test. (a) geometry. (b) experimental setup. (c) experimental results, the failure probability determined during the experiments is plotted versus the Weibull stress at failure. A very good agreement is found between the experiments and a Weibull law with $\mathrm{m}=10.3$ and $\sigma_{o}=368 \mathrm{MPa}$

\subsection{Application: 1D model}

This Weibull law is firstly employed to predict the risk of failure in the ceramic layer of the DBC substrate as a function of the thicknesses of the layers of this substrate and of the main characteristics of the materials. Initially, a 1D model is used. Up to now, the reference temperature $T_{o}$, for which the stresses inside the copper and ceramic layers is equal to zero, is not known. In this first analysis, it is assumed that $T_{0}$ is equal to the temperature at which the DBC substrate is soldered onto the base plate (about $250^{\circ} \mathrm{C}$ ). Therefore, residual stresses appear within the DBC at room temperature. In the future, it is planned to measure these residual stresses at room temperature using X-ray diffraction. The two layers of copper have a total thickness $t^{C u}$ and a width $w^{C u}$, while 
the thickness of the layer of ceramic is $t^{A N}$ and its width $w^{A N N}$. The same total strain is assumed for the three layers since they are bonded together. Plane strain conditions are assumed. The total strain is the sum of a mechanical strain and of a thermal strain $\varepsilon_{\theta}$. The behaviour of the aluminium nitride layer is elastic, while copper is elastic-plastic, with a yield stress $\sigma_{Y}$ and a hardening rate $\mathrm{H}$. The solder between the base plate and the lower layer of copper is assumed to fully accommodate interfacial shear strains, therefore:

$$
\begin{aligned}
& \varepsilon=\varepsilon_{e}^{C u}+\varepsilon_{p}^{C u}+\varepsilon_{\theta}^{C u}=\varepsilon_{e}^{A I N}+\varepsilon_{\theta}^{A I N} \text { and }\left(t^{A I N} w^{A I N}\right) \sigma^{A I N}+\left(t^{C u} w^{C u}\right) \sigma^{C u}=0 \\
& \text { where }: \varepsilon_{e}^{C u}=\frac{1-v_{C u}^{2}}{E_{C u}} \sigma^{C u} \text { and } \varepsilon_{e}^{A I N}=\frac{1-v_{A I N}^{2}}{E_{A \mathbb{N}}} \sigma^{A \mathbb{N}}
\end{aligned}
$$

and the Tresca criterion is used : $f=\left|\sigma^{C u}\right|-\sigma_{Y}-R \quad$ where $d R / d \varepsilon_{p}^{C u}=H$

With this simple set of equations, the stress inside the ceramic layer and the associated probability of failure can be determined during thermal cycling as a function of the parameters of the problem, the thicknesses $t^{C u}$ and $t^{A I N}$ of the layers, the initial temperature $T_{o}$ at which the DBC is initially soldered onto the base plate, the maximum and minimum temperatures $T_{\min }$ and $T_{\max }$ of thermal cycles, the yield stress $\sigma_{Y}$ and the hardening rate $H$.

A few conclusions can be drawn from this schematic analysis. If there is no plastic deformation, and if $T_{o}$ is above $T_{\max }$, then the ceramic layer is always in compression. On the contrary, if plastic deformation occurs during the initial cooling phase, from $T_{o}$ to $T_{\min }$, then the stresses within the layer of ceramic is not function of $T_{o}$ anymore, but of the thermo-elastic constants of the materials, of the yield stress of copper and of the thicknesses $t^{C u}$ and $t^{A I N}$. The characteristics of the cyclic elastic plastic behaviour of copper are of key importance in this case. For instance, if the material displays an isotropic hardening, the stress range in the ceramic layer increases cyclically until the cycle is fully elastic. With $\mathrm{H}=5 \mathrm{GPa}$ and $\sigma_{Y}=50 \mathrm{MPa}$, for instance, 20 cycles are required for the stress in the ceramic layer to reach its maximum value. In such a case, the brittle fracture of the ceramic (from a natural defect) may therefore occur after a few thermal cycles.

Finally, the saturation stress in the ceramic layer (Fig. 5a) and the corresponding failure 
probability (Fig. 5b) increase rapidly as the thickness of the copper sheet increases, the thickness of the ceramic layer being kept constant $(635 \mu \mathrm{m})$. Then a maximum value is reached when $t^{\mathrm{Cu}}$ is high enough to get a plastic deformation during of the layers of copper at each cooling phase. Above this value the failure probability diminishes when $t^{\mathrm{Cu}}$ increases. The DBC substrates used in this study have a thickness of their layers of copper equal to $300 \mu \mathrm{m}$. The probability of failure is close to its maximum in that case. Obviously DBC substrates built with thinner layers of copper would display a better resistance to thermal loading.

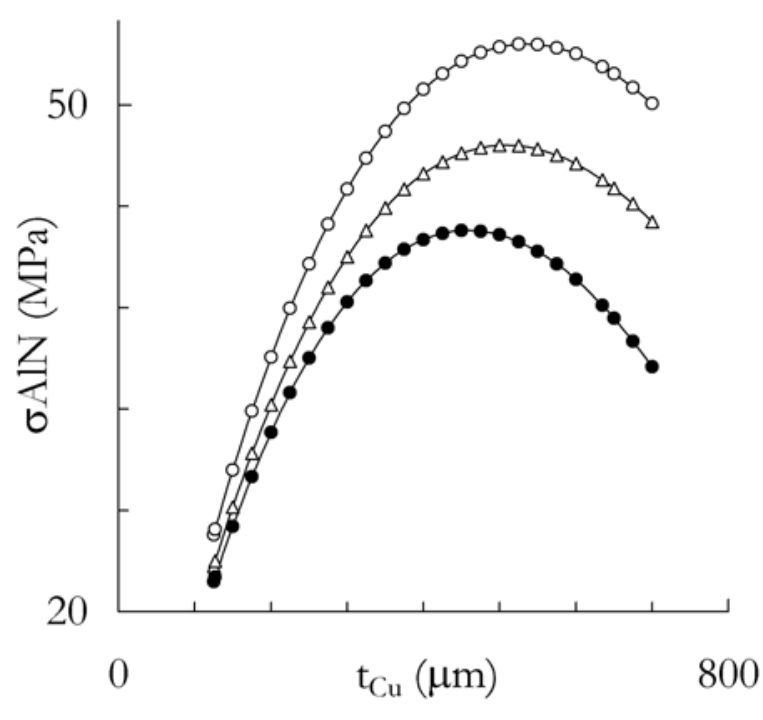

(a)

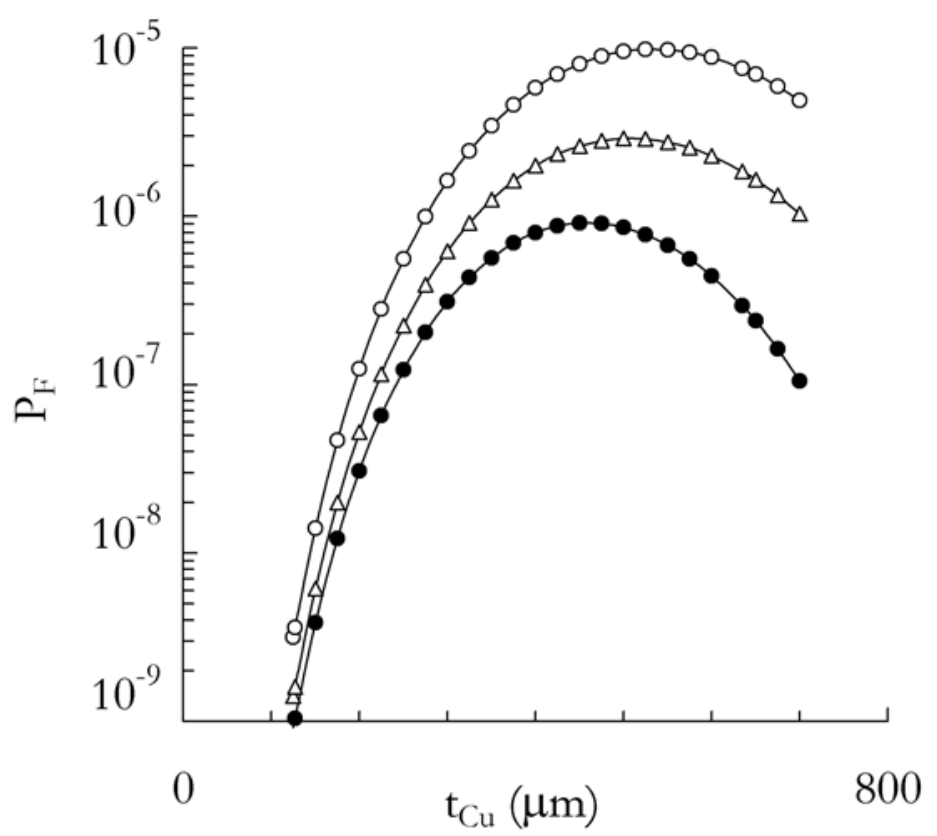

(b)

Figure 5: $t^{A I N}=635 \mu \mathrm{m}, w^{C u}=w^{A I N}=L=80 \mathrm{~mm}$, black circles: $\sigma_{Y}=194 \mathrm{MPa}$ and $H=0$, empty circles: $\sigma_{Y}=180 \mathrm{MPa}$ and $H=0$, triangles : $\sigma_{Y}=180 \mathrm{MPa}$ and $H=6500 \mathrm{MPa}$. (a) maximum principal stress component in the ceramic layer, (b) failure probability.

In addition, it is found that the failure probability varies significantly with the flow stress in copper. This can be easily understood since when plastic deformation occurs within the layers of copper during thermal cycling, the stress inside the copper layers and inside the aluminium nitride layer is controlled by the flow stress in copper.

As a conclusion of this schematic analysis of the problem, it can be said that, provided that copper is plastically deformed during cooling after the assembly process of the DBC substrate, the determination of the initial residual stresses inside the DBC substrate is not crucial. On the contrary, it is of key importance to characterize the cyclic elastic-plastic behaviour of the copper sheet employed for the DBC substrate and to optimize the geometry of the substrate. And finally, it 
appears that the geometry of usual DBC substrates could be optimized so as to reduce their failure probability.

Real DBC substrates display also notches, created by the chemical etching of the upper layer of copper, that induce stress concentrations inside the ceramic layer. Therefore, a finite element model is set up so as to determine the maximum principal stress within the aluminium nitride layer, using a more realistic geometry for the DBC substrate and a suitable elastic-plastic constitutive model for copper. The Weibull criterion is then used to post-treat the finite element computations. The Weibull law identified for aluminium-nitride is applied to each finite element in the ceramic layer and the weakest link theory is used to cumulate the failure probabilities for the whole model as follows:

$$
P_{F}(V)=1-P_{S}(V)=1-\exp \left(\sum_{i=1}^{N}-\frac{V_{i}^{E F}}{V_{o}}\left(\frac{\sigma_{i}^{E F}}{\sigma_{0}}\right)^{m}\right)
$$

Where $V_{i}^{E F}$ is the volume of the $i^{t h}$ finite element of the ceramic layer and $\sigma_{i}^{E F}$ is the positive part of the maximum principal stress in that element.

In these computations, the mesh size was adjusted so that the volume of each finite element remains above $0.07 \mathrm{~mm}^{3}$ in the major part of the model.

In other respects, the notches created by chemical etching are sharp and can be considered as geometric singularities. Actually, stresses and strains at the notch roots do not converge when the mesh size diminishes. Using finite element computations, it is shown that the gradient of the maximum principal stress component is higher than $4 \mathrm{~mm}^{-1}$ within a distance of $100 \mu \mathrm{m}$ to a geometric singularity. Since the Weibull law was characterized experimentally for stress gradients below this value, the elements within a distance of $100 \mu \mathrm{m}$ from a geometric singularity (Fig. $3 \mathrm{a}$ ) are excluded when the Weibull failure probability is calculated (Eq. 8). In return, these elements are used in a LEFM based failure criteria (§4).

This restriction makes sense since the Weibull approach is used to determine the risk of failure from natural defects of the ceramic and applies only in areas where stress and strain gradients remain moderate. When the stress gradient is large, in the vicinity of a geometric singularity, that singularity is assumed to be a much more efficient initiation site than a natural defect. In such a case, a LEFM based criterion should be used in preference to a Weibull law. 


\section{Crack initiation, growth and failure at geometric singularities.}

\subsection{Assumptions}

The second mechanism of failure considered here is the brittle fracture of the ceramic layer initiated from a small fatigue crack close to the upper interface between copper and ceramic. This problem was studied using the finite element method and the Abaqus code. For this purpose, the thickness of the layer of ceramic was set equal to $635 \mu \mathrm{m}$, the thickness of the upper layer of copper was fixed at $300 \mu \mathrm{m}$, while the other is fixed at $400 \mu \mathrm{m}$. The mesh size varies from $30 \mu \mathrm{m}$ down to $1 \mu \mathrm{m}$ at the geometric singularities (Fig. 6). 2D axisymmetric conditions are employed so as to reduce computation times.

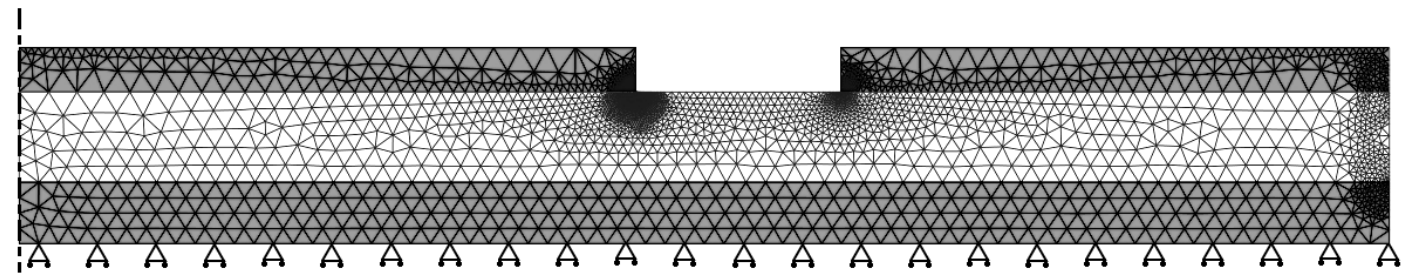

(a)

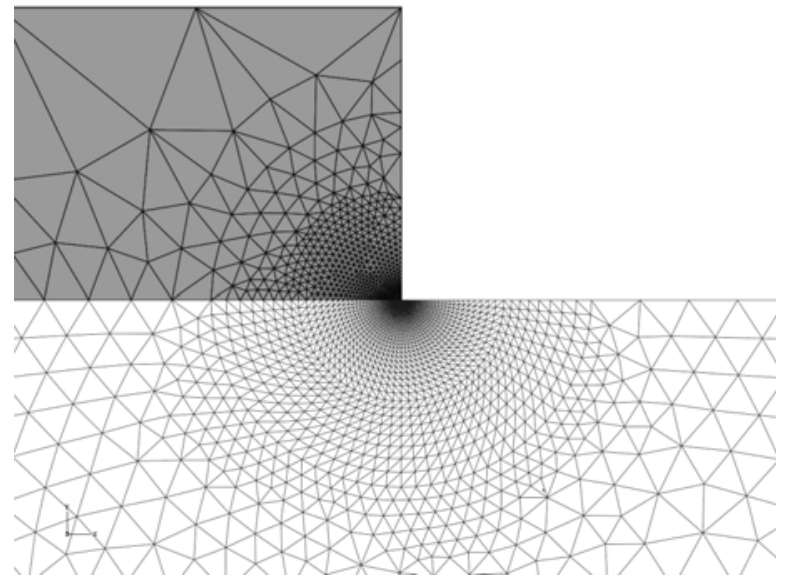

(b)

Figure 6: (a) general view of the FE model. $t_{C u}=300 \mu \mathrm{m}, t_{A I N}=635 \mu \mathrm{m} . \mathrm{L}=10 \mathrm{~mm}$, axisymmetric conditions. (b) detail of the mesh around a geometric singularity.

The material parameters employed for the two materials are gathered in Table 1. The copper was assumed to be elastic-plastic with a non-linear kinematics and isotropic hardening law (Table 1). The expansion coefficients were found in the literature. The parameters $E, v, R_{0}, C, \gamma, Q$ and $b$ of the copper constitutive model were determined using a tensile test and a cyclic tensile test 
performed on samples extracted from a thin sheet of copper $(\mathrm{t}=127 \mu \mathrm{m})$ used in DBC substrates (Fig. 7). Unfortunately, the geometry of the samples did not allow performing strain-imposed pushpull tests. The identification of the coefficients $C, \gamma, Q$ and $b$ is therefore questionable, in particular $\mathrm{Q}$ and b, but at least simulations and experiments are in reasonable agreements. All these coefficients were assumed to remain constant between $-50^{\circ} \mathrm{C}$ and $+180^{\circ} \mathrm{C}$, which is valid for the ceramic, but might be questionable for copper. More experiments are planned in the future to better characterize the cyclic behaviour of copper.

Table 1:Material parameters employed for copper and AIN.

\begin{tabular}{|l|ll|l|}
\hline \multirow{4}{*}{ Copper } & Young's modulus & $130 \mathrm{GPa}$ \\
\cline { 2 - 4 } & Poisson's ratio & 0.24 \\
\cline { 2 - 4 } & Thermal expansion & $16.10^{-6} /{ }^{\circ} \mathrm{C}$ \\
\cline { 2 - 4 } & Initial yield stress & Ro & $180 \mathrm{MPa}$ \\
\cline { 2 - 4 } & Kinematic hardening parameter $\quad \mathrm{C}$ & $602600 \mathrm{MPa}$ \\
\cline { 2 - 4 } & Kinematic hardening rate & $\gamma$ & 2300 \\
\cline { 2 - 4 } & Isotropic hardening amplitude & $\mathrm{Q}$ & $30 \mathrm{MPa}$ \\
\cline { 2 - 4 } & Isotropic hardening rate & $\mathrm{b}$ & 100 \\
\hline & Young's modulus & $320 \mathrm{GPa}$ \\
\cline { 2 - 4 } & Poisson's ratio & 0.24 \\
\cline { 2 - 3 } & Thermal expansion & $5.10^{-6} /{ }^{\circ} \mathrm{C}$ \\
\hline
\end{tabular}

It is useful to make clear that, by the moment, finite element simulations are employed to give prominence to the main trends. It is not aimed at predicting the fatigue life, for instance, but at indicating how the geometry or the manufacturing process could be modified so as to increase the fatigue life of the modules. 


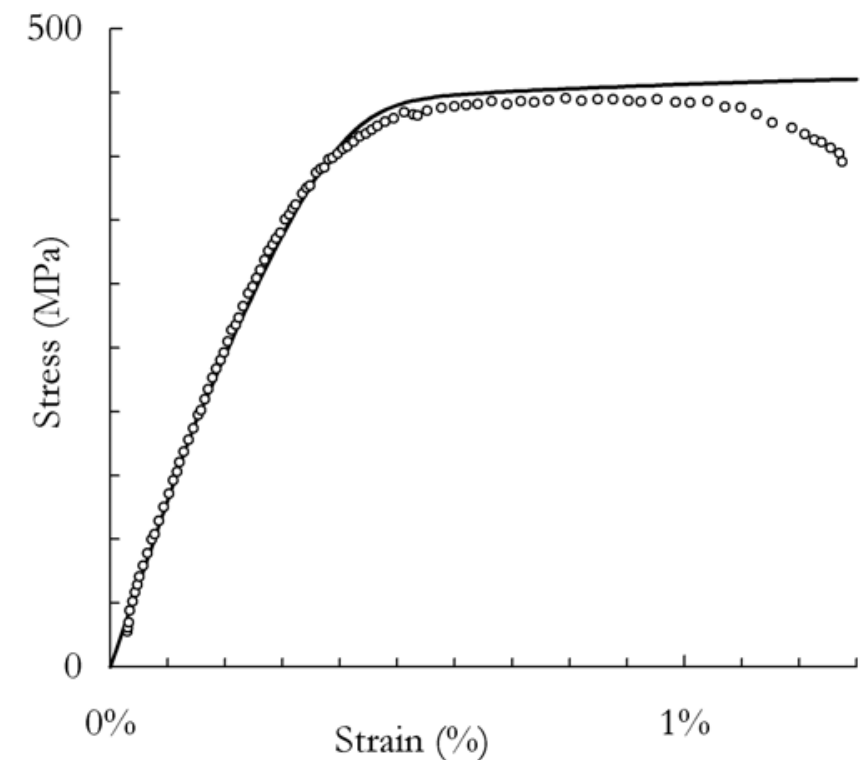

(a)

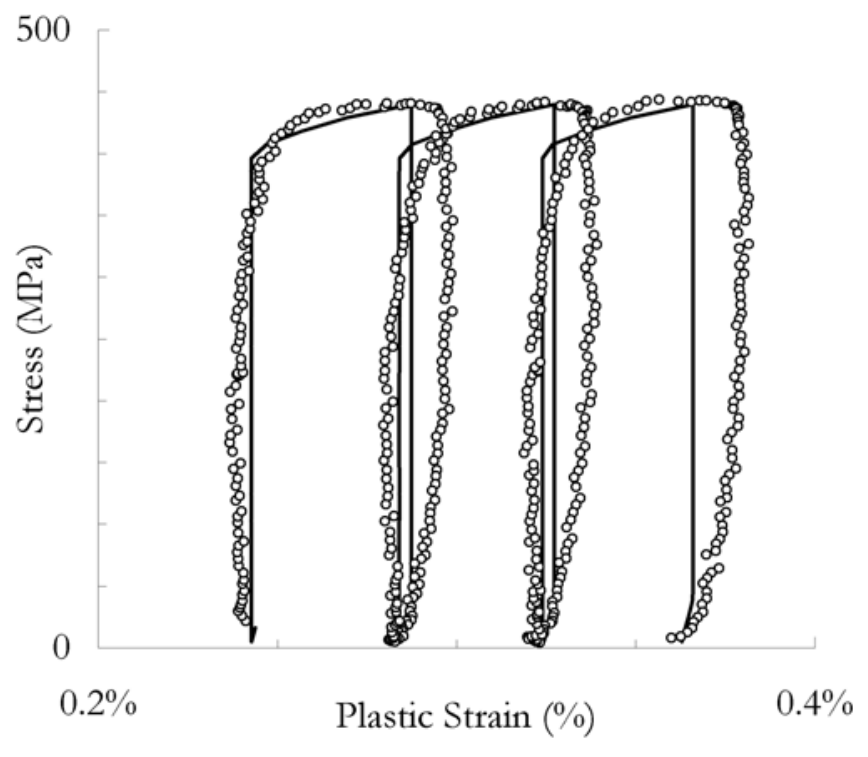

(b)

Figure 7: Tensile tests performed on thin sheets of copper (thickness of $127 \mu \mathrm{m}$ ), similar to those employed to build DBC substrates. The strain is measured using a strain gauge. Symbols : Experiments. Lines : Simulations. (a) strain controlled monotonic tensile test and (b) stress controlled cyclic tensile test, the minimum stress is $10 \mathrm{MPa}$, the maximum stress is increased by $10 \mathrm{MPa}$ every three cycles.

At the singularities created by chemical etching, stresses and strains in the ceramic layer do not converge when the mesh size diminishes. Therefore, a crack initiation or a failure criterion based on local stresses or strains cannot be applied. As a matter of fact, in linear elastic media, not only crack tips but also vertices of internal corners are singular [4,5]. Similar configurations are also encountered in contact problems [6,7]. In those cases, it was shown that the stress field can be represented by the product of a shape function $r^{\lambda} f(\theta)$ and of a generalized stress intensity factor [8]. Various authors [6;8] have employed generalized stress intensity factors successfully to characterize stress fields in the vicinity of singularities that are not cracks.

In 1971, Bogy [5] derived an analytical solution for an internal corner at an interface between two semi-infinite elastic materials. This solution allows determining the order of the singularity $\lambda$ of the stress field in the vicinity of the vertex. The theoretical value calculated using Bogy's equations for an interface between Copper and AlN with an open angle of $90^{\circ}$ in copper is $\lambda=-0.42$. The order of the singularity $\lambda$ is varying around this value if the angle varies around $90^{\circ}$ (Fig. $8 \mathrm{a}$ ) and tends to $\lambda=-0.487$ when the angle tends to zero (ideal crack). However, the problem studied here is somehow different from that analyzed by Bogy since the model is not semi-infinite and since the layer of copper is capable of plastic deformation. 
Therefore, the finite element method was also employed to determine the order of the singularity $\lambda$. For these computations the angle is fixed at $90^{\circ}$. Stresses were extracted from an elastic-plastic FE computation. Only the elements within the first $100 \mu \mathrm{m}$ from the vertex and inside the layer of ceramic are now considered (i.e. those that are not used for the Weibull approach). The shear stress is used for this analysis because it is not perturbed by the T-stress. The product of the shear stress by $r^{-\lambda}$ is plotted versus the angular position $\theta$ in Fig 8 (b and c). The values obtained for different radii $r$ tend to fall on the same curve when $\lambda$ is set equal to -0.5 (Fig. 8 b). The least square distance $d_{\lambda}$ between the curves was determined for various values of $\lambda$. The best agreement is found for $\lambda=-0.55$ with $d_{-0.55}=4.85 \%$. In any cases, a better agreement between is found for $\lambda=-0.5$ with $d_{-0.5}=5.12 \%$ (Fig. 8a) than for $\lambda=-0.42$ with $d_{-0.42}=6.76 \%$ (Fig. 8 c).

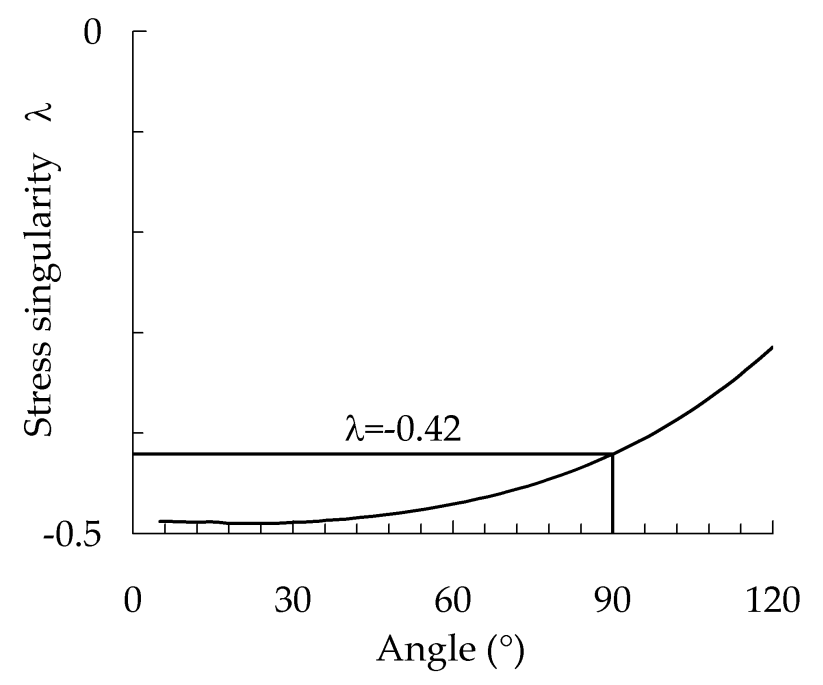

(a) 


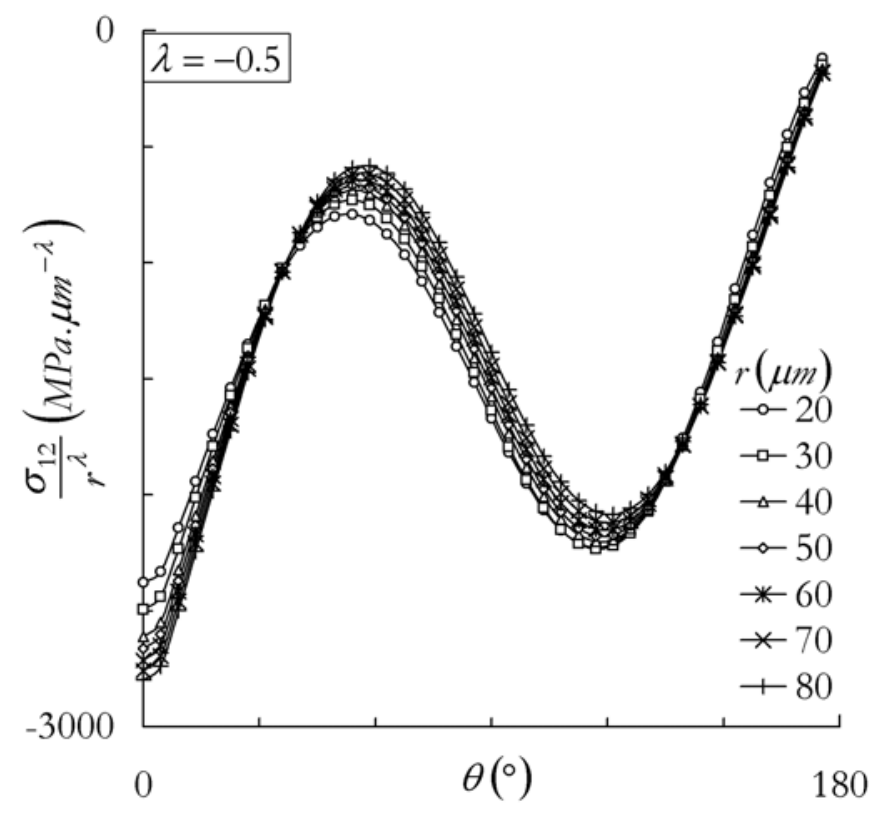

(b)

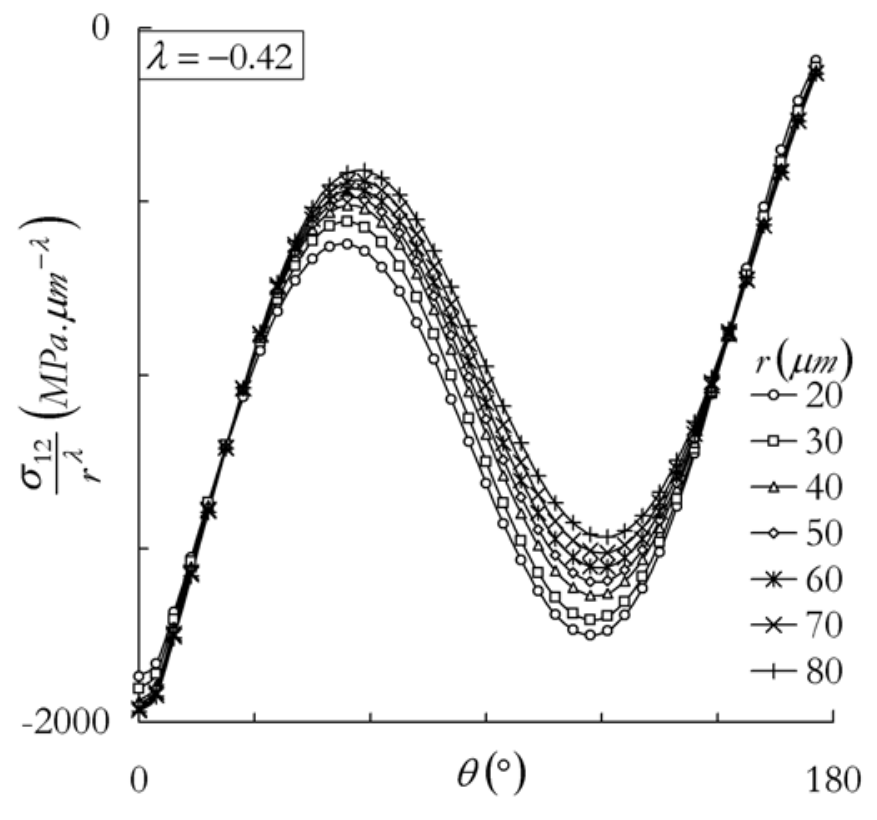

(C)

Figure 8: Determination of the order of the geometric singularity. (a) using the equations of Bogy [5] that applies to an open angle at the interface between two elastic media.(b and c) using FE stress fields.

The product $r^{-\lambda} \sigma_{12}$ is plotted against the angular position of the node in the vicinity of a geometric singularity. (b) $\lambda=-0.5$ (singularity of an ideal crack in an homogeneous media), (c) $\lambda=-0.42$ (solution of Bogy for a $90^{\circ}$ sharp angle in copper at a copper/AlN interface).

Therefore the singularity $\lambda$ of the stress field in the studied problem can be considered as equal to that of an ideal crack in an homogeneous media. With that hypothesis, it becomes possible to extract the mode I and mode II stress intensity factors by correlating the displacement fields in the ceramic layer using the Westergaard displacement functions. For this purpose, 2878 finite elements nodes were used. The average correlation error is below $10 \%$. The coordinate system of the Westergaard displacement functions is such as that the "crack plane" corresponds to the interface and the "crack front" to the vertex of the internal corner in copper.

Using the FE method, $K_{I}$ and $K_{I I}$ are determined at each time increment in the coordinate system attached to the interface. Next, the stress intensity factors $K_{I}^{*}(\alpha)$ and $K_{I I}^{*}(\alpha)$ for an infinitesimal crack branch inclined by an angle $\alpha$ from the interface $[9,10,11]$ can be calculated using the approximated formulas [12]:

$$
K_{I}^{*}(\alpha)=C_{11} K_{I}+C_{12} K_{I I} \quad \text { and } \quad K_{I I}^{*}(\alpha)=C_{21} K_{I}+C_{22} K_{I I}
$$

Where 


$$
\begin{aligned}
& C_{11}=\frac{1}{2} \cos \frac{\alpha}{2}(1+\cos \alpha)\left(1+0.051\left(\frac{\alpha}{2 \pi}\right)^{4}\right) \\
& C_{12}=-\frac{3}{2} \cos \frac{\alpha}{2} \sin \alpha\left(1+0.060\left(\frac{\alpha}{2 \pi}\right)^{2}+0.064\left(\frac{\alpha}{2 \pi}\right)^{4}\right) \\
& C_{21}=\frac{1}{2} \cos \frac{\alpha}{2} \sin \alpha\left(1-0.048\left(\frac{\alpha}{2 \pi}\right)^{2}+0.033\left(\frac{\alpha}{2 \pi}\right)^{4}\right) \\
& C_{22}=\frac{1}{2} \cos \frac{\alpha}{2}(3 \cos \alpha-1)+0.242\left(\frac{\alpha}{2 \pi}\right)^{2}-0.085\left(\frac{\alpha}{2 \pi}\right)^{4}
\end{aligned}
$$

The inclination angle $\alpha_{\max }$ for which the mode II stress intensity factor is equal to zero $K_{I I}^{*}\left(\alpha_{\max }\right)=0$ is also determined and the corresponding value of the mode I stress intensity factor $K_{I}^{*}\left(\alpha_{\max }\right)$ is stored. $K_{I}^{*}\left(\alpha_{\max }\right)$ is then compared with the fracture toughness of the ceramic layer so as to determine whether the brittle fracture of the ceramic layer occurs or not. And finally, if we assume that the fatigue crack growth rate of interfacial cracks increases if their stress intensity factor increases, then an equivalent stress intensity factor has to be defined. As a matter of fact, since interfacial cracks are submitted to mixed mode loading conditions, the crack driving force is to be defined as a function of $K_{I}$ and $K_{I I}$. For this purpose, various expressions of an equivalent stress intensity factor range are available in the literature [13]. However, no consensus has been reached on this subject. Therefore, it has been chosen (quite arbitrarily) to employ the range $\Delta K_{I}^{*}\left(\alpha_{\max }\right)$ as an indicator of the crack driving force in mixed-mode fatigue. $\Delta K_{I}^{*}\left(\alpha_{\max }\right)$ is function of $\Delta K_{I}$ and $\Delta K_{I I}$ (Eq. 10), and is defined as the range of the mode I stress intensity factor range, on a plane inclined at an angle $\alpha_{\max }$ from the interface, for which $\Delta K_{I I}^{*}\left(\alpha_{\max }\right)=0$.

\subsection{Summary}

The brittle fracture of the ceramic layer from a singularity should occur if:

$$
\max _{t}\left(K_{I}^{*}\left(\alpha_{\max }\right)\right)=K_{I c}^{A I N}
$$

Alternatively, the brittle fracture of the ceramic layer can also initiate from a defect in the ceramic layer, with a probability calculated as follows: 


$$
P_{F}(V)=1-\exp \left(\sum_{i=1}^{N}-\frac{V_{i}^{E F}}{V_{o}}\left(\frac{\sigma_{i}^{E F}}{\sigma_{0}}\right)^{m}\right)
$$

And finally, if these two criteria are not fulfilled, a thermal fatigue crack may propagate along the upper copper/ceramic interface from a geometric singularity until its size is long enough to promote the brittle fracture of the ceramic. In such a case the fatigue life of the DBC substrate should be correlated to $\Delta K_{I}^{*}\left(\alpha_{\max }\right)$.

\subsection{Results}

Once the method is set up it allows computing the evolutions of the mode I stress intensity factor $K_{I}^{*}\left(\alpha_{\max }\right)$ with the number of cycles for various loadings histories.

In Fig. 9 a, for instance, the applied temperature is plotted versus the number of cycles. Two cases are considered. First, only thermal fatigue cycles are applied with $\mathrm{T}_{\max }=+180^{\circ} \mathrm{C}$ and $\mathrm{T}_{\min }=-$ $30^{\circ} \mathrm{C}$, then a second case is considered for which 3 "overloads" cycles are applied $\left(\mathrm{T}_{\max }=+180^{\circ} \mathrm{C}\right.$ and $\mathrm{T}_{\min }=-70^{\circ} \mathrm{C}$ ) prior to thermal cycling.

The failure probability was calculated in both cases. If three overloads are applied initially, the failure probability is increased by a factor 2.5 during the application of the overloads and then reduced by nearly a factor 2 during the application of thermal fatigue cycles (Fig. $9 \mathrm{~b}$ ). It is important to avoid a brittle fracture of the ceramic layer during the initial cooling phase. In the present case, the risk of failure remains small.

The mode I and mode II stress intensity factors extracted from FE computations using the displacement correlation method are plotted in Fig. 9 c and Fig. 9 d. The mean value of the mode I stress intensity factor diminishes after the application of overloads cycles, because of the introduction of internal stresses. An opposite effect is observed for $K_{I I}$. The application of overloads should therefore tend to close tiny cracks initiated from the singularity and growing along the interface.

In addition, the inclination angle $\alpha_{\max }$ that maximizes the mode I stress intensity factor $K_{I}^{*}\left(\alpha_{\max }\right)$ and for which $K_{I I}^{*}\left(\alpha_{\max }\right)=0$ is found equal to $57^{\circ}$. The maximum value of $K_{I}^{*}\left(\alpha_{\max }\right)$ is reached during overloads cycles and is equal to $9 \mathrm{MPa} \cdot \mathrm{m}^{1 / 2}$. This value is above the fracture toughness of 
aluminium nitride (4 MPa.m ${ }^{1 / 2}$ ) found in the literature, which indicates that the ceramic layer should break immediately, at an angle of $57^{\circ}$ from the interface, which is not the case in reality. However, AlN employed in DBC substrates is not pure (Fig. $3 \mathrm{~d}$ ), while the value of $K_{I c}^{A I N}$ found in the literature refer to a pure AlN. Therefore it is likely that the fracture toughness of the AlN-based ceramic layer of DBC substrates is higher than $9 \mathrm{MPa} \cdot \mathrm{m}^{1 / 2}$.

The evolution of the stress intensity factor range along a plane inclined at $57^{\circ}$ from the interface $\Delta K_{I}^{*}\left(\alpha_{\max }\right)$ is plotted in Fig. 9 e. The application of three thermal overload cycles leads to a reduction of $\Delta K_{I}^{*}\left(\alpha_{\max }\right)$ by about $10 \%$ during subsequent thermal fatigue cycles. It is worth to mention that the stress intensity factor range $\Delta K_{I}^{*}\left(\alpha_{\max }\right)$ during thermal fatigue cycles diminishes with the number of initial overloads, and is nearly stabilized after 3 overloads. As a matter of fact, the layers of copper are elastic-plastic. Plastic deformation appears during overload cycles in the vicinity of geometric singularities. If plastic deformation remains constrained, the hysteresis cycle in each point should tend to a stabilized cycle. However, this stabilized cycle is not reached at the first cycle. The number of cycles required to get a stabilized cycle depend on the material elasticplastic behaviour and on the plastic strain amplitude in each cycle. In the present case, three overload cycles almost stabilizes the material response. Additional overload cycles are not useful and can even be detrimental since they contribute to damage the component.

Finally, it is also aimed at indicating how overload cycles would modify the fatigue life of the components. For this purpose, it is assumed (though this assumption is questionable) that the fatigue crack growth rate of interfacial cracks obeys the Paris law. Therefore the effect of overloads on the crack growth rate and hence on the fatigue life, can be determined from the effect of overloads on the stress intensity factor range. Two main problems arise. A crack growing at the interface is subjected to mixed mode loading conditions and secondly $K_{I}$ is maximum when $K_{I I}$ is minimum. Therefore, an equivalent stress intensity factor range has to be calculated from the evolutions of $K_{I}$ and $K_{I I}$ during thermal fatigue cycles. Two criteria were used, the results are reported in $\operatorname{Table}^{\circ} 2$.

If the equivalent stress intensity factor range is calculated using the formulae of Tanaka (cited in [13]), there is nearly no reduction of the crack's driving force by the application of overloads. But this criterion is not suitable for out of phase mixed-mode cycles. If we use the range $\Delta K_{I}^{*}\left(\alpha_{\max }\right)$ of 
the stress intensity factor on a plane inclined at an angle $\alpha_{\max }$ for which $\Delta K_{I I}^{*}\left(\alpha_{\max }\right)=0$, then it accounts for mixed mode loading conditions. In such a case, the application of overloads induces a reduction of the crack's driving force by about $8 \%$.

Table 2:Material parameters employed for copper and AIN.

\begin{tabular}{|l|c|c|c|}
\hline & $\begin{array}{c}\text { Without } \\
\text { overloads } \\
\Delta K_{e q}(\operatorname{MPa} \sqrt{m})\end{array}$ & $\begin{array}{c}\text { With overloads } \\
\Delta K_{e q}^{O L}(\operatorname{MPa} \sqrt{m})\end{array}$ & $\left(\frac{\Delta K_{e q}}{\Delta K_{e q}^{O L}}\right)^{3.5}$ \\
\hline$\Delta K_{I}$ & 4.70 & 4.36 & \\
\hline$\Delta K_{I I}$ & 4.85 & 4.83 & \\
\hline$\Delta K_{e q}=\Delta K_{I}^{*}\left(\alpha_{\max }\right)($ Eq. 10) & 7.96 & 7.36 & 1.31 \\
\hline $\begin{array}{l}\Delta K_{e q}=\left(\Delta K_{I}^{4}+8 \Delta K_{I I}^{4}\right)^{1 / 4} \\
(\text { after Tanaka cited in [13]) }\end{array}$ & 8.38 & 8.28 & 1.04 \\
\hline
\end{tabular}

So as to evaluate the effect of the reduction of $\Delta K_{e q}$ by the application of overloads on the fatigue crack growth rate and hence on the fatigue life, we assume that the Paris law applies with a Paris exponent $m=3.5$. The fatigue life is expected to increase by typically a factor 1.3 if $\Delta K_{I}^{*}\left(\alpha_{\max }\right)$ is used as the crack's driving force.

In practice, the constitutive behaviour of the copper sheet in the DBC substrate is not known precisely. Therefore, the yield stress of copper was also varied in order to evaluate its effect on $K_{I}^{*}\left(\alpha_{\max }\right)$. It was observed that overloads should promote a retardation effect, provided that the plastic zone of the overload remains constrained. As a matter of fact, if the copper layers plastically deform at each cycle, the residual stresses left by the overload cycles vanish within a few cycles. On the contrary, if the yield stress and the hardening law is such as that plastic deformation remains constrained during thermal fatigue cycles, then an overload tends to reduce $K_{I}^{*}\left(\alpha_{\max }\right)$. This is the case for the results plotted in Fig. 9. Furthermore, the reduction of $K_{I}^{*}\left(\alpha_{\max }\right)$ vary significantly according to the cyclic behaviour of copper, which is not known with enough precision at the moment. According to FE computations, hard copper sheets would be better for this application. 


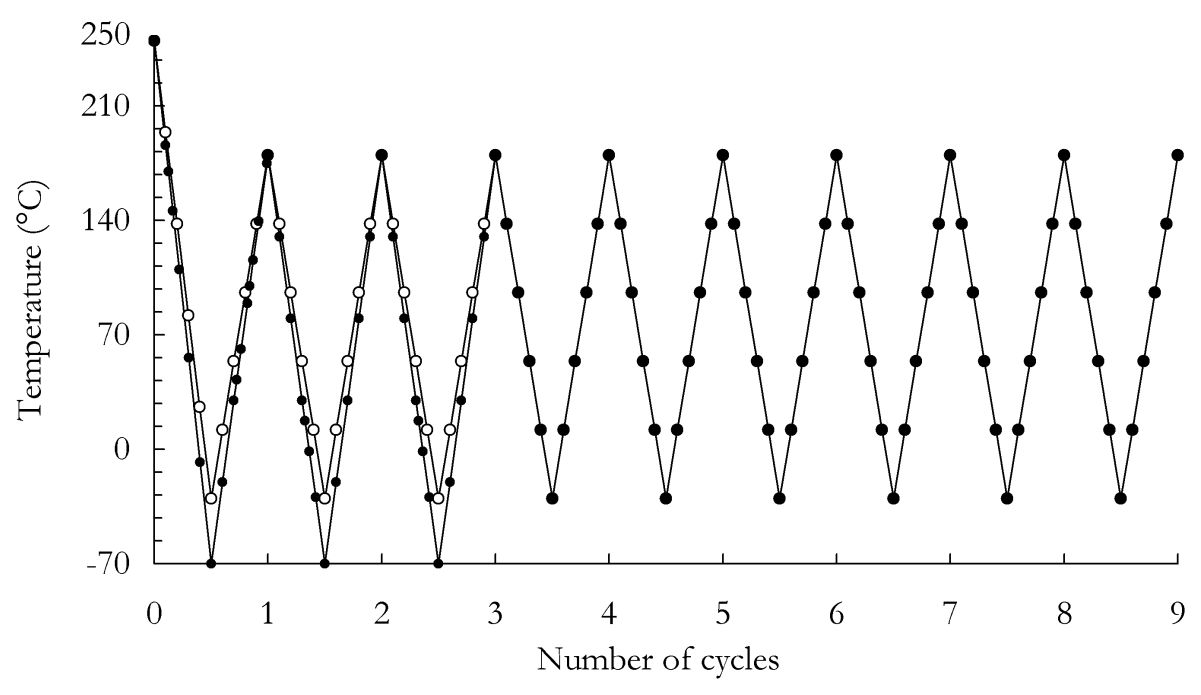

(a)

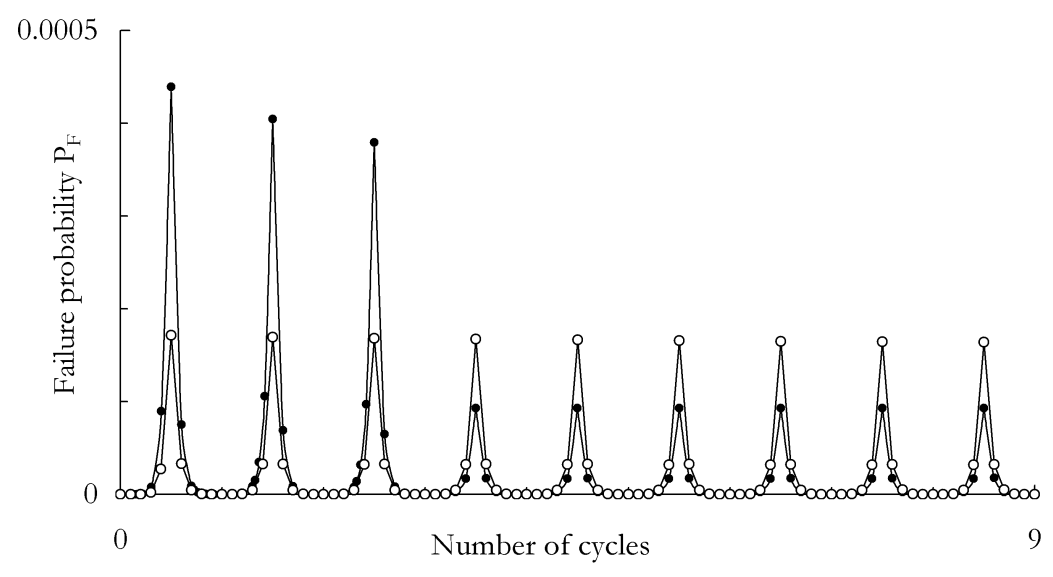

(b)

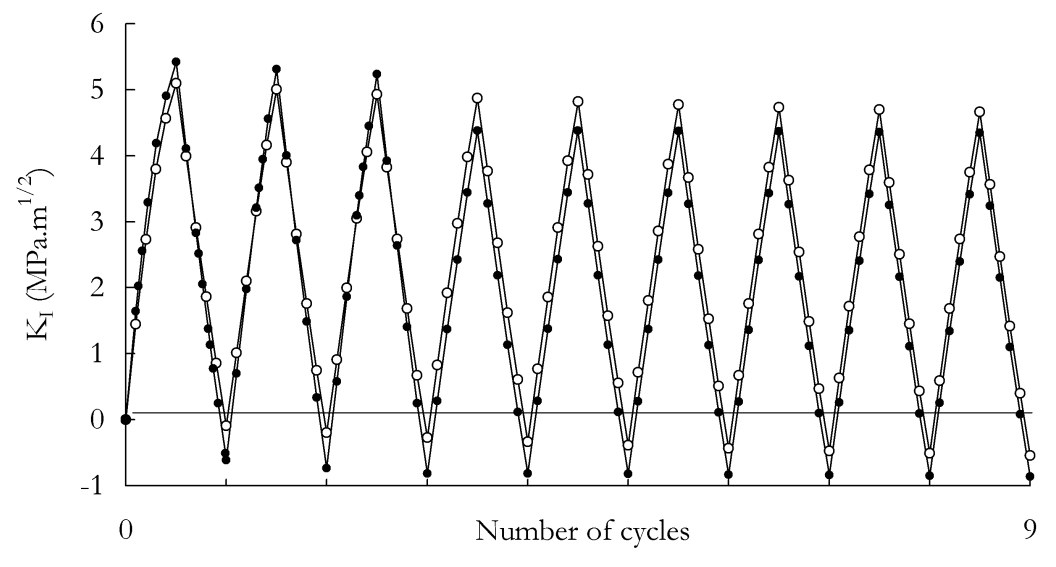

(c) 


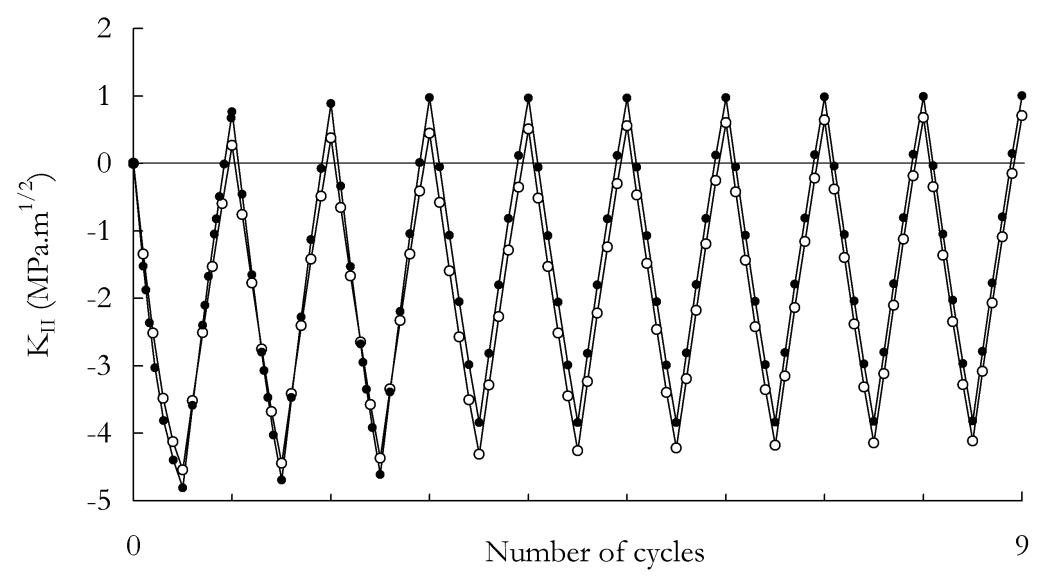

(d)

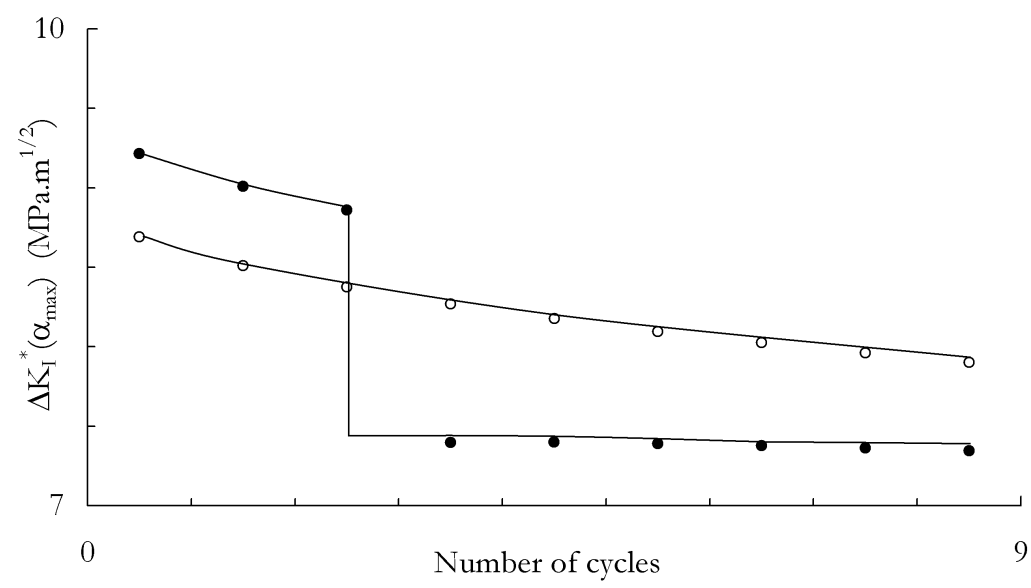

(e)

Figure 9: (a) Applied temperature histories, empty symbols $T_{\max }{ }^{-}+180^{\circ} \mathrm{C}-T_{\min }=-30^{\circ} \mathrm{C}$. Black symbols 3 overloads cycles are applied $\left(T_{\max }+180^{\circ} \mathrm{C}-T_{\min }=-70^{\circ} \mathrm{C}\right)$, before applying thermal fatigue cycles: $\left(T_{\max }{ }^{-}+180^{\circ} \mathrm{C}-T_{\min }=-30^{\circ} \mathrm{C}\right)$. (b) Weibull failure probability (c) mode I and (d) mode II stress intensity factors in the coordinate system attached to the interface. (e) mode I stress intensity factor range $\Delta K_{I}^{*}$ for a crack branch inclined at an angle such as that $K_{I I}{ }^{*}=0$.

\subsection{Experiments}

Even if numerical results remain qualitative only, they indicate that applying a few "overload" cycles before cycling diminishes the stress intensity factors in the vicinity of the singularities and should therefore tend to increase the fatigue life of the DBC substrates.

Therefore, experiments were also conducted to evaluate the effect of such overload cycles on the fatigue life of DBC substrates. The DBC substrates were submitted to three overload cycles at $\mathrm{T}_{\min }=-70^{\circ} \mathrm{C}$ and $\mathrm{T}_{\max }=180^{\circ} \mathrm{C}$ before applying thermal fatigue cycles with $\mathrm{T}_{\min }=-30^{\circ} \mathrm{C}$ and $\mathrm{T}_{\max }=180^{\circ} \mathrm{C}$. A set of 3 substrates each including 7 copper lines electrically connected were tested simultaneously. The capacitance of each element (Fig 10 symbols) and the average capacitance of 
the 21 elementary capacitances (Fig. 10 thick line) was measured periodically (Fig. 2a). This experiment can be directly compared with that performed by Dupont [1] using the same substrates and the same thermal fatigue cycles (Fig. 2 b) but without overloads (Fig. 10 dotted line).

First, the initial cooling phase did not break the components, neither from a defect in the ceramic layer nor from geometric singularities. Secondly, a significant increase of the fatigue life is obtained. While the fatigue life was ranging between 20 and 40 cycles for thermal fatigue cycles only, it grows over 350 cycles if three overloads cycles are applied prior to thermal fatigue cycling.

In practice, other technologies are used to increase the fatigue life of substrates (dimples, ceramic Si3N4) but these results indicate that very simple methods that take advantage of the thermo-mechanical properties of the materials can be very efficient and low cost.

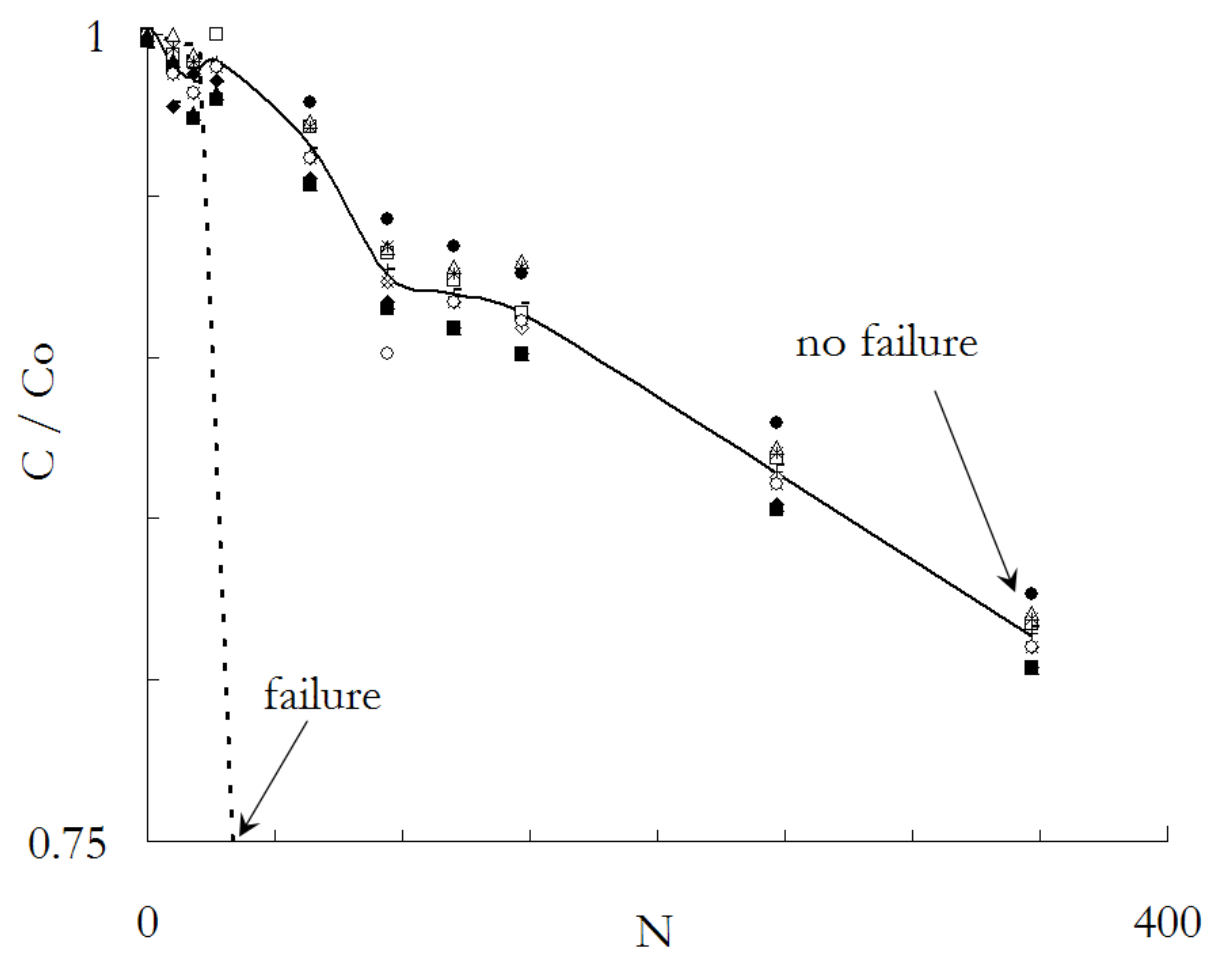

Figure 10: Evolution of the capacitance $C(p F)$ during thermal cycling versus the number of thermal cycles. The capacitance $C$ is non-dimensioned by the initial capacitance Co. Thick line and symbols, with overloads: three initial "overloads cycles" are applied $\left(T_{\min }=-70^{\circ} \mathrm{C}\right.$ and $\left.T_{\max }=-70^{\circ} \mathrm{C}\right)$ before thermal fatigue cycling $\left(T_{\min }=-30^{\circ} \mathrm{C}\right.$ and $\left.T_{\max }=-70^{\circ} \mathrm{C}\right)$. After 347 cycles the samples have not failed.

Dotted lines, without overloads[1] : the failure occurs between the $40^{\text {th }}$ and the $50^{\text {th }}$ cycle.

\section{Conclusions and prospects}

The thermo-mechanical behaviour of DBC substrate for electronic devices was studied using the 
FE method in order to better understand and to model the mechanisms at the origin of failure. These substrates are submitted to thermal fatigue. The final objective is to propose a method to optimize the geometry and the materials in DBC substrates so as to maximize their fatigue life and reliability.

The failure probability of the ceramic layer was modelled by a Weibull law. To identify the parameters $m$ and $\sigma_{o}$ of the aluminium nitride layer, three points bending tests were performed for three sample geometries in order to identify precisely the volume change effect on the failure probability. A good agreement is found between the Weibull law and the set of experimental results, with $m=10.3$ and $\sigma_{0}=368 \mathrm{MPa}, V_{o}$ being set at $1 \mathrm{~mm}^{3}$. This law can be used as a posttreatment routine of $\mathrm{FE}$ computation so as to determine the risk of failure of the aluminium nitride layer from a natural defect of the ceramic.

It was observed that stress and strain fields are singular at the vertices of the chemically etched area in the upper copper layer. It was determined that the singularity $\lambda$ of these fields is close to 0.5, which allows working within the framework of LEFM. With that hypothesis the stress fields near the singular points are characterized by their mode I and mode II stress intensity factors. It was shown using FE computations, that the knowledge of the elastic-plastic constitutive behaviour of the copper layer is of key importance to predict the stress intensity factor evolutions for variable amplitude thermal histories. Provided that the plastic zone in the copper layer around the singular points remains constrained, a few initial overloads reduce the maximum equivalent stress intensity factor range during subsequent thermal cycles. This effect induces fatigue crack growth retardation.

Experiments were therefore conducted to check this idea. DBC substrates of power electronic modules were submitted to thermal fatigue cycles. For the same thermal cycles, the fatigue life is at least 7 times higher when 3 overloads cycles are applied prior to thermal fatigue cycling.

Experiments should also be conducted so as to determine more precisely the cyclic elasticplastic behaviour of the copper sheet and the toughness of the aluminium nitride layer in DBC substrates. With these experimental data, quantitative (not only qualitative) computations will be performed so as to optimize the geometry of the DBC substrate in order to maximize its fatigue life and its reliability.

\section{Acknowledgements}

The author would like to acknowledge the French Research Agencies (DGA and CNRS) and the 
Farman institute of the Ecole Normale Supérieure de Cachan for their financial support and their encouragements to set up interdisciplinary research programs.

\section{References}

[1] L. Dupont, (2006), Contribution à l'étude de la durée de vie des assemblages de puissance, PhD thesis of ENSC, Cachan, June 2006.

[2] A. Houssam, et al (1995), Room temperature tensile and flexural strength of ceramics in AlNSiC system, J. of the Eur. Cer. Soc., Vol. 15, I. 5, 1995, pp 425-434.

[3] Y. Nagatomo and T. Nagase (2000), The Study of the Power Modules with High Reliability for EV Use, 17th EVS conf., Montreal, October 2000.

[4] Khrapkov AA (1970). The first basic problem for a notch at the apex at an infinite wedge. Int J Fract 1970,7(4):373-82.

[5] Bogy D.B. (1971) On the plane elastostatic problem of a loaded crack terminating at a material interface, J.Appl.Mech., 38, 1971, 911-918.

[6] Giannakopoulos A.E, Lindley T.C, Suresh S. (1997) Aspects of equivalence between contact mechanics: Theoretical connections and a life-prediction methodology for fretting-fatigue, Overview, Acta mater. Vol. 46, No. 9, pp. 2955-2968, 1998

[7] Johnson K.L, (1985) Contact Mechanics, Cambridge University Press, Cambridge, 1985.

[8] D. Leguillon, (2002) Strength or toughness? A criterion for crack onset at a notch, EJMA-S E, Volume 21, Issue 1, 2002, Pages 61-72.

[9] Bilby BA, Cardew GE, Howard IC. (1977) Stress intensity factors at the tips of kinked and forked cracks. In: Taplin DMR, editor, Fracture 1977, vol 3. New York: Pergamon Press: 1977.

[10] Cotterell B. Rice JR. (1980) Slightly curved or kinked cracks. Int J Fract 1980, 16: 155-69.

[11] Melin S. (1994) Accurate data for stress intensity factors at infinitesimal kinks. J Appl Mech 1994, 61: 467-70.

[12] Hill DA. Kelly PA. Dai DN. Korsunsky AM. (1996) Solution of Cracks Problems, the distributed dislocation technique. Kluwer Academic Publishers, DORDRECHT, 1996.

[13] Qian, J., Fatemi, A., (1996) Mixed mode fatigue crack growth: A literature survey, Engineering Fracture Mechanics, Vol. 55 (6), pp. 969-990 